\title{
O PENSAMENTO ABISSAL E O GENOCÍDIO DA POPULAÇÃO INDÍGENA: Os contextos na pandemia de Covid-19
}

\author{
THE ABYSSAL THOUGHT AND THE GENOCIDE OF THE INDIGENOUS \\ POPULATION: The contexts in the pandemic of Covid-19
}

\author{
Giovanna Maria Brito Gonçalves ${ }^{1}$ \\ João Carlos Da Cunha Moura ${ }^{2}$
}

\section{RESUMO}

$\mathrm{O}$ presente artigo discorre acerca da gigantesca linha que divide a sociedade e detém o poder de promover a invisibilidade do outro lado. A localização de determinadas pessoas neste lado das linhas abissais, thes confere acesso aos benefícios para que se desenvolva, enquanto os que estão do outro lado são excluídos dessa possibilidade. O Estado brasileiro constantemente pautou o tratamento usado para com os povos indígenas, em uma franca tentativa de extermínio, como uma relação historicamente genocida. Com o início da pandemia, houve a afetação especialmente das populações mais vulneráveis, e no caso de povos tradicionais, se tornou uma importante ferramenta de manutenção e potencialização do genocídio indígena. Esta pesquisa se desenvolveu na forma de pesquisa bibliográfica, utilizando de artigos, livros, além de outras obras publicadas sobre o objeto de estudo. $\mathrm{O}$ presente estudo se perfaz para o entendimento da divisão em zonas que se concentram do lado de cá e do lado de lá da linha abissal e a dinâmica existente quanto a invisibilização, o genocídio indígena e a influência da pandemia de covid-19, para o agravamento da mortandade.

Palavras-chave: Linha Abissal. Genocídio Indígena. Pandemia de Covid-19.

\section{ABSTRACT}

This article discusses the gigantic line that divides society and holds the power to promote invisibility on the other side. The location of certain people on this side of the abyssal lines gives them access to the benefits for them to develop, while those on the other side are excluded this possibility. The Brazilian state constantly based on the treatment used for indigenous peoples, in a frank attempt at extermination, as a historically genocidal relationship. With the onset of the pandemic, there was the affectation especially of the most vulnerable populations, and in the case of traditional peoples, has become an important tool for maintaining and potentiating indigenous genocide. This research was developed in the form of bibliographical research, using articles, books, and other works published on the object of study. The present study is made for the understanding of the division in areas that are concentrated on the side of here and on the other side of the abyssal line and the existing dynamics regarding invisibility, indigenous genocide and the influence of the covid-19 pandemic, for the worsening of death.

Keywords: Abyssal Line. Indigenous Genocide. Covid-19 pandemic.

${ }^{1}$ Graduanda no curso de Direito pelo Centro Universitário Dom Bosco - UNDB.

${ }^{2}$ Docente do curso de Direito pelo Centro Universitário Dom Bosco - UNDB; Mestre em Direito e Instituições do Sistema de Justiça pela Universida de Federal do Maranhão; Doutorandoem Direito pela Universidad Nacionalde Mar del Plata (Argentina). 


\section{INTRODUÇÃO}

A presença de uma gigantesca linha que divide a sociedade detém o poder de promover a invisibilidade do outro lado, para que possa se sustentar e promover a manutenção dos interesses e benefícios daqueles que querem o seu pleno funcionamento. Dentro do véu da invisibilidade social, grupos minoritários sofrem com os efeitos de políticas reiteradas de apagamento.

Em um cenário de pretensa normalidade, seria possível afirmar com uma certa firmeza a evolução social no sentido de extinção dessa linha e suas consequências, tendo em vista a inexistência do exercício de visualização por partes de certos atores. Entretanto, as dinâmicas da sociedade frente ao acontecimento da Pandemia de Covid-19 foram alteradas, evidenciando as disparidades presentes nessa sociedade dividida e o quanto sujeitos portadores de determinados marcadores sociais são os que mais sofrem em razão da agressão à sua existência.

Desdeo início dapandemia até os dias presentes, a doença tem seguido um ritmo acelerado de propagação em todo o planeta. O crescimento do contágio tem trazido impactos econômicos, sociais e de saúde, especialmente quando se trata de marcadores sociais de raça, classe e gênero, características ligadas a vulnerabilidade de inúmeros grupos populacionais. Assim, a necessidade quanto ao debate a respeito dessas características é imperiosa para a mais correta compreensão e superação dos desafios apresentados nesse cenário (ESTRELA ET AL, 2020, p. 3432).

A imagem construída de povos indígenas como inimigos, sem que estes pudessem ter lugar defala, ou fossem ao menos enxergados pela sociedade, refletiu ao longo dos séculos, fortalecendo uma política de extinção, esta de iniciativa inclusive do próprio Estado. No tangente as populações tradicionais, o advento pandêmico agravou um cenário nefasto de exclusão e destruição constante, que se iniciou com o processo de colonização.

Este artigo fora desenvolvido com base em pesquisa bibliográfica que, segundo Marconi e Lakatos (2011), condiz com o levantamento de obras publicadas, estas no formato de livros, revistas, entre outros impressos, com a finalidade de promover a ligação entre o pesquisador e aquilo que fora produzido a respeito do objeto de estudo em questão.

Desse modo, o presente estudo apresenta em seu primeiro tópico o dimensionamento acerca da separação do conjunto social pelas linhas abissais, em consonância com a obra de Boaventura Sousa Santos. No segundo tópico, destaca-se a invisibilização por linhas abissais como fomento de práticas genocidas diante desse cenário. Por fim, no terceiro tópico trata sobre a utilização do advento da pandemia como ferramenta para o genocídio indígena.

\section{DESENVOLVIMENTO}




\subsection{A SEPARAÇÃO DO CONJUNTO SOCIAL PELAS LINHAS ABISSAIS.}

Toda construção discursiva cientificista em que há a inserção do direito, no entendimento de Silva (2017, p.107), está posta em identificação com a lei, objeto de conhecimento científico do direito, pois no campo do direito moderno, a manifestação das invisibilidades se revela a medida em que a instituição delineia aquilo que é legal ou ilegal, conforme o direito oficial estatal ou o direito internacional. Essa instituição, constituído deste lado da linha do pensamento abissal, significa afirmar que o legal ou ilegal são as configurações da existência diante da lei, que por tal motivação, essa distinção se consagra com caráter universalista.

Em contrapartida, esse mesmo pensamento se apresenta do outro lado da linha, este composto pelos conhecimentos populares, classificado como local onde não há validade como conhecimento real, existindo somente crenças, opiniões, idolatria, conhecimentos intuitivos ou subjetivos, que podem ser apenas matéria abstrata para a investigação científica. Esse lado, é caracterizado pelo direito moderno como território sem e fora da lei, ou do legal e ilegal em que essas determinações são realizadas em consonância com direitos não reconhecidos oficialmente (SILVA, 2017, p.107).

A obra de Boaventura Sousa Santos se constrói em um pensamento essencialmente dialético, na medida em que afirma e propõe a coexistência de concepções opostas. Isto remete a unidade de contrários, que significa a existência de um pressuposto conflito social, que por sua vez é o objeto dadialética. Esta, em seu turno representa que em um mesmo objeto possa haver opostos em co-presença (PINHEIRO; BUSSINGUER, 2016, p.905).

Como delineia Santos (2019, p. 351), as epstemologias que elaboram e propagam certos tipos de saberes que buscam reproduzir as linhas abissais encaixam-se como Norte. A localização central das linhas abissais e das lutas que se insurgem contra separações e dominação, importa no posicionamento oposto da chamada sociabilidade colonial em relação a sociabilidade metropolitana, e o resultado quanto os processos de exclusões sociais abissais e não-abissais.

O não confrontamento das estruturas que fornecem a manutenção das linhas abissais, ocasiona o ocultamento e destruição do que seria a sociologia das ausências, afirmadas como a realidade social, política e cultural, como origina também a destruição da sociologia das emergências, ocultando possibilidades, potencialidades e alternativas (SANTOS, 2019, p. 352).

O fascismo do apartheid social se apresenta como a segregação social daqueles excluídos por meio do uso da cartografia urbana como instrumento de separação entre áreas selvagens e áreas civilizadas. As áreas ou zonas selvagens, são os locais onde está presente o estado de natureza delineado por Hobbes, essas zonas que estão em constante confronto civil interno são percebidos 


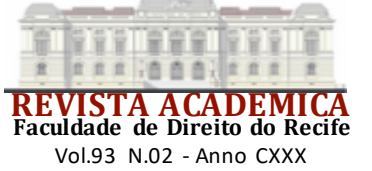

em inúmeras grandes cidades em todo a parte Sul global. As áreas ou zonas civilizadas correspondem as do contrato social, vivendo sob ameaça constante das zonas selvagens. Estes últimos, se modificaram em fortalezas semelhantes aos feudos, com a justificativa de defesa, caracterizando assim os novos modelos de segregação urbana, composto principalmente por condomínios fechados, por exemplo (SANTOS, 2007a, p.81).

Perspectivas subalternas se revestem precisamente de divergências, uma vez que foram guiados em um contexto cultural distinto, onde, nesse caso, a visibilidade se apresenta como um enigma, e a ocorrência de perspectivas assimétricas se torna frequente (SANTOS, 2019, p. 251). Isto se traduziria como um entendimento de mundo que possui olhares discrepantes quanto a sociedade, de acordo com que lado da linha esteja disposto, que produz conflitos, em que haja a valorização de um olhar ao invés de outro.

Tornar invisível, permite a ocultação das opressões e discriminações, faz com que não sejam enxergadas consequentemente inúmeras maneiras de opressão como o racismo e o sexismo (SANTOS, 2007b, p.52). Isto impossibilita, ou ao menos obstaculiza, a efetuação de importantes debates, profundos e poderosos, para a tentativa de encontro de verdadeiras resoluções à essas questões.

Dessa forma, observa-se que o exercício de poder, se apresenta de seis modos basilares, por mais possa haver outros tipos, de forma que "patriarcado, exploração, fetichismo das mercadorias, diferenciação desigual, dominação e intercâmbio desigual são [..] instrumentos analíticos que podem ser vistos como modos de produção de poder e de saber" (SANTOS, 2007b, p.62).

No âmbito dessas formas de categorização, o autor dispôs como espaços-tempos nos quais se desencadeiam a operação desses poderes. O espaço-tempo doméstico, em que se observa o patriarcado e as ligações sociais de sexo; o espaço-tempo produtivo, onde a exploração atua como poder; o espaço-tempo estrutural do mercado, no qual se apresenta como modo de poder o fetichismo da mercadoria; o espaço-tempo assinalado à comunidade, em que atua como modo de poder a distinção daqueles que pertencem aquele local e aqueles que não pertencem, que seria a diferenciação desigual; o espaço-tempo da cidadania, comumente associado ao espaço de caráter público, em que a forma de poder é a dominação, a existência de uma solidariedade direcionada verticalmente entre o Estado e seus cidadãos; e por fim, o espaço-tempo mundial em que a forma de poder seria o intercambio desigual, referente a cada concentração social em escala global (SANTOS, 2007b, p.61-62).

Apresenta-se, assim, um dos efeitos da aplicação daquilo que é denominado por Santos (2007A, p.81), como fascismo social, este que pode ser encarado como a nova forma do estad o de 


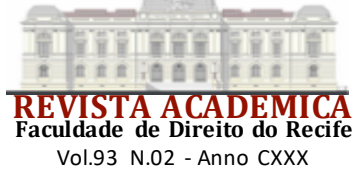

natureza, e se espalha assegurado pelo contrato social de dois modos, sendo estes o précontratualismo e o pós-contratualismo.

Aquilo que se assemelha com o pré-contratualismo se concentra no impedimento do acesso à cidadania para grupos sociais, que estavam em um estado de expectativa concreta de nela se inserir. Quanto ao pós-contratualismo se revela como um processo no qual os grupos sociais e seus interesses são excluídos do contrato social sem que tenha perspectiva alguma inserção ou reingresso, aqui exemplifica-se por meio dos grupos de trabalhadores e membros das classes mais pobres que não são incluídos no contrato social por causa da supressão de seus direitos econômicos e sociais, contornando-os em grupos sociais descartáveis (SANTOS, 2007A, p.81).

As populações mais vulneráveis e marginalizadas, são produtos desses fenômenos sociais, morando em locais precários, não sendo somente este o problema enfrentado na vivência destas pessoas, pois também não há o acesso à serviços básicos de saúde infraestrutura. Sendo imperioso que novas estratégias sejam criadas para promover o acesso a saúde dessas populações (ESTRELA ET AL, 2020, p. 3435). Se destaca tal direito em razão da precariedade com o qual é prestado, como a educação e infraestrutura, uma vez que aos invisíveis pouco ou nada é destinado, assim, são despidos de condições mínimas, já que suas problemáticas não são enxergadas.

Uma vez que, ante essa divisão, existe uma categorização em sub-humanidade, na qual estão postos os índios, os quilombolas, os aborígenes, dentre outros, que estão esquecidos e marginalizados, que são ligados as tradições. E existe, uma categorização de humanidade, formada por um grupo distinto, que não aceita a integração desses indivíduos (KRENAK, 2020).

Nota-se, por exemplo, que os conhecimentos tradicionais se apresentam para o saber científico como religiões concentradas em lugares para aquelas que alcançaram escala mundial. Nesse modo, o saber científico se anuncia como verdade única, até que caia por terra diante de outro saber que lhe supere. Resta claro que quand o se trata de ciência, esse é sinônimo tão somente de saber científico, send o necessário adicionar o adjetivo tradicional para que isto signifique outros saberes, de forma que se apresentaria como ciência tradicional (CUNHA, 2009, p. 301 - 303)

A isto se assinala que o domínio se revolve por uma estrutura de hierarquia, que promove a sistemática da exclusão, onde também está além dos limites exteriores, aquilo que se encontra embaixo, não existindo de tal forma, iniciando em uma configuração na qual é descartável, desprezado, e então desaparece (SANTOS, 2007b, p.63).

O silenciamento de um grupo, trata-se de uma forma de domínio de extrema importância, uma vez que o movimento contrário implica na possibilidade de dar voz e "aparência" aos invisíveis, (SANTOS, 2019, p. 256). Além do fato da dominação se instaurar de tal forma, isso 


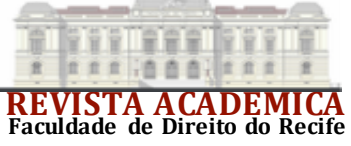

Vol.93 N.02 - Anno CXXX

representa tolhimento da efetiva participação social de muitos sujeitos, presentes no outro lado da linha abissal.

De tal forma, dá-se importância aquilo que é prioridade para uma pequena parcela, em que coisas se tornam mais preciosas que a vida do outro, posto o apego aos bens e a sede insaciável de acúmulo de riquezas, ou pelo menos a tentativa desesperada e desumanizante de mantê-las, assim como os privilégios oriundos de todo o processo exploratório.

Um meio viável para a resolução da situação que se apresenta se concretizaria por meio do reconhecimento de alternativas que representassem sistemas de produção, organizações socioeconômicas de caráter popular, modelos econômicos, dentre outras formas que seguiriam essa formulação, todas maneiras que forma ocultadas e desvalorizas por uma lógica individualista e centrada na concentração de riquezas (SANTOS, 2007b, p. 36).

Contudo, a separação entre as zonas civilizadas e selvagens está se transformando em um tipo de critério de aplicação geral na sociabilidade, em uma nova dinâmica de espaço e tempo hegemônicos que transcorre todas as relações sociais, econômicas, políticas e culturais e que por tal razão é ordinário nos âmbitos de caráter estatal ou não. (SANTOS, 2007a, p. 80).

Cada vez mais sujeitos são excluídos, iniciando no sistema desigual e finalizando no sistema de exclusão, em que estão subordinados a irem e permanecerem fora, a serem expulsos do contrato social, da sociedade civil, que é valorizada e visibilizada. Está acontecendo a desestabilização daqueles que um dia estiveram firmes em seus papeis e expectativas sociais, bem como a manutenção desse cenário, e por tal, pode-se afirmar que é presente uma crise no contrato social, em que a expulsão de contingentes cada vez maiores de pessoas para o estado de natureza (SANTOS, 2007b, p. 63-88).

Santos enuncia que "linhas abissais são traçadas tanto no sentido literal quanto no metafórico" (2007a, p.79). A modernidade ocidental, em um quadro mais amplo, somente será capaz de expandir-se na proporção em que viole todos os princípios sobre os quais estruturou a legitimidade histórica do padrão da regulação/emancipação deste lado dalinha. De tal forma, existe a violação dos direitos humanos para que possa haver a sua defesa, os processos democráticos são desbaratados para que seja garantida a sua salvaguarda e a vida é um objeto passível de fácil eliminação em nome da sua preservação (SANTOS, 2007a, p.79).

A organização de uma possível emancipação social, detém uma problemática central que se delineia por temas tensionados como o alinhamento e independência social, o estabelecimento de ordem e a concepção de progresso, entre um conjunto social que detém inúmeros problemas, como também a expectativa de os solucionar de maneira viável (SANTOS, 2007b, p. 17). 


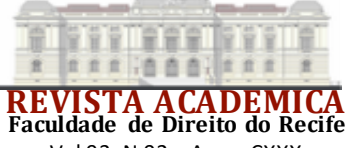

Vol.93 N.02 - Anno CXXX

Levando em conta que a conexão profunda entre o desenvolvimento dos direitos humanos concentrados no ocidente e o percurso colonialista, ao longo da história, fazer uma interpretação diatópica é uma tarefa de tradução difícil. Empreender tal análise usando como ponto de partida a perspectiva do Sul é um início, contudo, este pode ser um falso ponto de partida se não houver a compreensão de que o Norte vem promovendo a desintegração do Sul desde os primórdios (SANTOS, 2010, p. 99).

Como afirma Santos (2010, p. 100), é evidente que na interpretação diatópica citada, admitir que houve um empobrecimento mútuo daquele assinalado como vítima e aquele assinalado como opressor, embora sejam largamente assimétricos, é uma premissa básica para que ocorra um diálogo intercultural.

A construção do pensamento pós-abissal estabelece o acontecimento da dialética entre a monocultura de saberes e uma ecologia de saberes. Onde vigora o típico conhecimento científico e conhecimentos tradicionais hegemônicos, corresponde a primeira, enquanto a segunda, detém em sua fundamentação conhecimentos não científicos a quem atribui visibilidade proveniente da lógica do pensamento abissal moderno, que considera que com a não existência de cientificidade não é possível haver forma alguma de conhecimento (PINHEIRO; BUSSINGUER, 2016, p.906).

O entendimento intercultural necessita se inicializar com hipótese de que as distintas culturas na realidade são interculturais, porém, associado ao entendimento de que as comunicações e trocas sempre se deram de maneira desigual e majoritariamente hostil ao diálogo universalista (SANTOS, 2010, p. 101).

Conforme o entendimento de Santos (2007a, p.90), a ecologia dos saberes corresponde a ideia formalizada de que há necessidade de uma modificação do pensamento das operações presentes e nas relações concretas na sociedade e na natureza que as diversas áreas do conhecimento proporcionam. Concentra-se, então, nos relacionamentos entre os saberes, nas organizações hierarquizadas que são geradas entre eles, visto que nenhuma prática com concretude seria possibilitada sem a presença dessas hierarquias.

Nessa senda, pode-se afirmar que a ecologia dos sujeitos seria então a integração daqueles que são desvalorizados a uma sociedade que de fato tenha construído pontes de inclusão sobre o abismo de separação social. Não havendo o lado de cá da linha abissal e o outro lado desta linha.

\subsection{A INVISIBILIZAÇÃO POR LINHAS ABISSAIS COMO FOMENTO DO GENOCÍDIO DE POVOS TRADICIONAIS.}




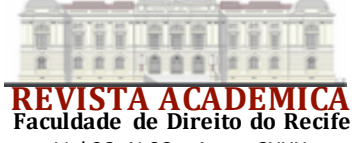

Vol.93 N.02 - Anno CXXX

A existência do que Santos (2007b, p. 22) chama de conhecimentos rivais se traduz na disposição que o Norte detém em efetuar a negação de validade dos saberes distintos do saber científico ou ainda trabalhar a inexistência destes que seriam os saberes populares, como os conhecimentos indígenas, a fim de alterá-los para o status de elemento de estudo e desenvolvimento do saber científico.

$\mathrm{O}$ autor apresenta a monocultura do saber e do rigor, que seria a ideia de que o conhecimento científico é somente o único que detém rigor, de forma a invalidar os outros conhecimentos, posto que não teriam o mesmo rigor. A monocultura realiza a redução do presente, pois ao eliminar o que está fora da esfera científica, acaba por eliminar muitos aspectos da realidade, visto que inúmeras características que formam as sociedades e as práticas nelas constantes se baseiam em conhecimentos populares, indígenas, dentre outros, que não são classificados como rigorosos ou minimamente importantes. Desse modo, todos as organizações sociais que estão pautadas em conhecimentos distintos do científico, são invisíveis. A monocultura, desde a disseminação imperialista, se embasa tão somente na ciência ocidental (SANTOS, 2007b, p. 29).

Como desvalorização de conhecimentos tradicionais advindos de outras esferas e culturas, que não as tipicamente ocidentais, conforme Cunha (2009, p. 305), diz-se que quanto as questões medicinais de diversos povos, esse saber não é inventivo, que se trata de uma simples descoberta, que pode até mesmo ser uma observação de outros primatas, ao implementar seu uso. Além disso, ocorre a depreciação utilizando como parâmetro o valor financeiro atribuído aos distintos saberes.

A exclusão exercida se contorna em inexistente e radical ao mesmo tempo, posto que os seres considerados subumanos não são cogitados elegíveis à inclusão social. Assim, essa exterioridade observada do outro lado da linha é, em sua verdadeira face, a consequência do seu relacionamento ao pensamento abissal, tanto como fundação quanto a negação da mesma (SANTOS, 2007a, p.76).

De forma que a estruturação da letalid ade, em quase sua totalidade, se perfaz por processos de inviabilização. A implementação do silêncio resulta em isolamento e abafamento de opiniões e posicionamentos. O sujeito conformado se torna o único tipo passível de integração social, falar sobre temáticas ligada a mortandade das minorias exige o rompimento com o silêncio (VERGNE; VILHENA;ZAMORA, 2015, p. 518).

O indivíduo invisível se torna o único bem-vindo, de modo que Vergne, Vilhena e Zamora (2015, p. 525), explicita que um efeito dessa conduta é a concepção de um lugar ao qual pertence o outro, caracterizad o como um não humano. A desnud ação de humanidade não se fixa tão somente na cor da pele, mas na atribuição valorativa aos hábitos, práticas tradicionais, meios de 
comunicação e maneiras de sentir. Há a transformação dos sujeitos em figuras semelhantes a animais, possibilitando o seu extermínio, uma vez que não se trata de um igual e sim do outro.

O pensamento abissal presente na modernidade, segundo Santos $(2007$, p.) é proeminente ao conseguir originar e radicalizar as diferenciações. Mesmo que haja uma profundidade nas distinções presentes e mesmo que sejam radicalmente dramáticas e que suas consequências se reflitam em um lado ou outro, elas são pertencentes a este lado da linha e se configuram de modo que torna invisível a linha abissal existente que lhes alicerçam. As distinções densamente visíveis que estruturam o cenário da realidade social deste lado da linha se fundamentam na invisibilidade das distinções entre este e o outro lado linha.

Essas designações aos diferentes lados e sua separação que lhes confere validade, podem ser observadas de forma fática na sociedade, ao validar ou invalidar a existência de pessoas pertencentes ou não a este ou aquele lado da linha. A localização desses sujeitos neste lado da linha lhes confere acesso aos benefícios mais básicos para que se desenvolva na sociedade, e estando do outro lado são excluídos da possibilidade de desenvolvimento.

Essa exclusão se completa com a utilização de ferramentas exterminadoras que devastam os invisíveis, de forma que minorias estão presentes de um lado, este que os torna passiveis de destruição, sendo o caso das populações indígenas a demonstração da ocorrência de genocídio sistemático ao longo de cinco séculos.

A denegatória sobre quaisquer vínculos existentes, que sejam minimamente comuns entre o conquistador e o nativo, constitui a asserção de que nos territórios colonizados possibilita-se o governo pautado na ilegalidade completa. $\mathrm{Na}$ visão dos invasores, a vida não civilizada nos seus termos, se trataria de apenas mais uma vida animal, um experimento espantoso, além de suas imaginações limitadas, que escapa de sua compreensão, consistindo em uma coisa alienígena (MBEMBE, 2016, p. 133).

O modelo exterminacionista, segundo Manduruku (2012, p. 27-28), operacionalizad o com a finalidade de destruição das populações indígenas, iniciou-se com a chegada dos europeus. Era o comum a ser aplicado, diante do conceito vigente de que os povos nativos não eram detentores de alma na visão cristã, e sua morte ordenada era uma missão divina. Ação que somente foi desautorizada no século XVI, com a consideração pela Igreja, de que indígenas teriam alma, nos termos cristãos, o que pouco significou diante da violência empregad a para o domínio territorial e expansão.

Este se trata de um período histórico longo, de dominação, violência, do início e fortalecimento de atos genocidas contra povos indígenas brasileiros, autorizados e regulamentados pelo governo dominante. Mesmo com a aplicação de outras formas de violação, foi um período 


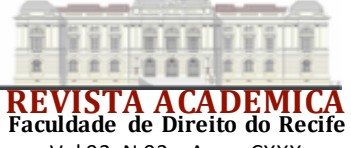

Vol.93 N.02 - Anno CXXX

marcado pela opressão física, com a extinção de grupos inteiros, causando uma limpeza étnica, para que esses espaços dessem lugar ao desenvolvimento de grupos que se afirmavam civilizados (MANDURUKU, 2012, p. 28). Promove-se a destruição dos invisíveis, para que somente estejam presentes os que se denominam como visíveis.

A criação da expressão genocídio somente fora efetivamente firmada até o pós Segunda Guerra, sendo empregada para classificar os crimes contra a humanidade, que se fundam na eliminação de um grupo determinado, havendo a efetiva regulamentação por meio da Convenção para a Prevenção e a Repressão do Crime de Genocídio, de 1948.

O genocídio é definido como atos praticados com a intenção de destruir totalmente ou parcialmente, um grupo nacional, étnico, racial ou religioso, que envolvem ações como: matar membros do grupo; causar lesão grave à integridade física ou mental de membros do grupo; submeter intencionalmente o grupo a condição de existência capazes de ocasionar-lhe a destruição física total ou parcial; adotar medidas destinadas a impedir os nascimentos no seio de grupo; e efetuar a transferência forçada de crianças do grupo para outro grupo (ONU, 1947).

Os sujeitos passivos ao genocídio, conforme Campos (2008, p. 92), são aqueles que integram um grupo étnico, racial, nacional e/ou religioso, na posição de membros desses grupos, sendo fundamental a integração a um desses agrupamentos e que aquele que figura como sujeito ativo desse ato, detenha consciência dessas condições.

No tocante a tipologia penal, se trata do aspecto especial existente na intenção de destruir, seja em parte ou o todo, o grupo pertencente a um ou mais delimitações acima citadas. Dessa forma, a prática da conduta sem esse dolo, não configura o crime de genocídio. Contudo, não se pode determinar que o agente tenha motivação pessoal para efetuar a eliminação, send o suficiente que haja compreensão da conduta como elemento de um planejamento constante a ação que objetivam o resultado intentado da extinção do grupo (CAMPOS, 2008, p. 95).

A constante submissão, de forma intencional de povos indígenas a condições que lhe ocasionam a destruição, mesmo que em parte configuram a prática genocida. Não estando limitadas a ações físicas violentas, havendo uma extensão invisibilizante que fomenta a possibilidade do extermínio.

Apercebe-se que são comuns episódios de violência empregada contra comunidades indígenas e seus integrantes, proveniente de racismo institucional, bem como outras formas de degradação e desrespeito a esses povos, tanto diretas como indiretas, estas presentes nas falas quanto nos atos do sujeito agressor, contudo, pouco se analisa no que se refere a esses aspectos nas mais diferentes áreas de estudo, enquanto face de racismo (MILANEZ et al, 2020, p. 2169). Desse $\underline{\text { modo, os avanços tímidos na compreensão dessa violência, resultam em políticas públicas }}$ 


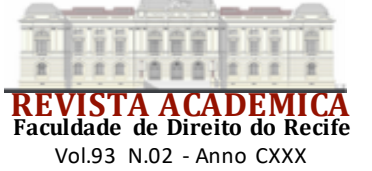

deficientes, que tem efeito reverso, propiciando a manifestação do desrespeito as populações indígenas.

Esse sacrifício presente na negação de uma parte da humanidade se concretiza como condição para a outra parte da humanidade aponte para si mesma a afirmativa como universal. Esta negação fundamental, de certo modo, é permissora de que tudo aquilo que é possível que se modifique na possibilidade de tudo, de outro modo, a criatividade empregada no pensamento abissal banaliza espontaneamente a pena de sua destrutividade (SANTOS, 2007a, p. 76).

O registro da existência de um outro sujeito, este oposto, como uma ameaça à vida, de forma que somente a sua extirpação biofísica significaria um ideal de segurança e preservação da vida do indivíduo ativo, se trata de um dos vários imaginários inerentes à soberania, intrínsecos a modernidade, de acordo com o pensamento de Mbembe (2016, p. 128-129).

Paira uma falsa sensação de simetria entre a aplicação de direitos e deveres na sociedade, pois em geral nos focamos excessivamente na cultura dos direitos humanos, deixando de lado os deveres humanos. A aplicação da simetria existe na não concessão de direitos àqueles que não se pode exigir deveres, se podendo-se permitir o usufruto de direitos para quem tem deveres (SANTOS, 2007b, p.41). Muito se exige de direitos, acerca também da existência do direito de retirar direitos alheios, de impedir quem não está dentro da configuração estabelecida da sociedade em acessá-la, manter do lado de lá da linha.

A atribuição de desconhecimento à realidade indígena, se trat a de um mito amplamente utilizado por legisladores quanto estes, por exemplo, tomam decisões que afrontam direitos indígenas, assim eximem-se de responsabilidades, utilizando de uma presumida ausência de conhecimento. Nesse sentido, somente seriam válidos conhecimentos advindos da elite acadêmica majoritariamente branca e não-indígena, sem levar em conta as demandas dos próprios indígenas. Dentro desse quadro, a alegada inexistência de conhecimento, seria a desconsideração dos efeitos estruturais do racismo ao regular a estruturação socioeconômica (MILANEZ et al, 2020, p. 2165).

A marginalização dos povos indígenas se dá de forma dissimulada, que Milanez et al (2020, p. 2171) destaca parecer-se, na observação de indivíduos alheios, a uma ação benéfica, nesse sentido, a experiência brasileira municia o racismo cordial e o acontecimento do chamado benefício racista, no qual sob a desculpa de exercer proteção ao sujeito ou ao seu direito, na realidade produz a discriminação e controle, assim há o disfarce contínuo do racismo.

A ideia colonialista de que uma parte da população deve viver segregada, foi naturalizada no imaginário brasileiro. A violência racial direcionada à população indígena é uma estratégia do Estado, que detém a finalidade de fortalecer sua segregação e exclusão. Observa-se que os territórios desses povos estão sendo invadidos pelo agronegócio e em constante ameaça pela 


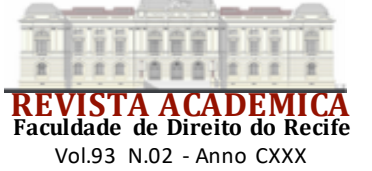

mineração, que avança sobre seus espaços, de modo a realizar a manutenção da relação de desiguald ade presente (MILANEZ ET AL, 2020, p. 2171).

Por essa razão, questões como a definição de linguagem proveniente de autores indígenas não significa somente uma epstemologia diversa, mas a representação de definições contrárias a hegemonia, as desestruturando e forçando a um aumento dos limites da observação e inquirição científica, de forma a ser enxergado. Estas construções indígenas apresentam uma epstemologia distinta, que contesta a produção de conhecimento dominante, e por tal, essa diferenciação se põe como autogestão e independência (OLIVEIRA; PINTO, 2011, p. 328).

A ambição da eliminação e seus efeitos não se apresentam de forma abstrata, se mostram por meio de dor e sofrimento. As marcas dessa violação reverberam ao longo da vida inteira dos sujeitos, sem que estes ao menos consigam externar o que sentem, assim excluem-se possibilidades distintas. O genocídio, como produto da segregação e aversão, não se concentra apenas nos efeitos ao corpo, posto que produz menores mortes antes mesmo do extermínio total de um grupo (VERGNE; VILHENA; ZAMORA, 2015, p. 526).

O ideal de que a humanidade vive, algo que Krenak (2019) chama de uma abstração civilizatória, alheia as raízes tradicionais e à terra, se mostra absurdo para o autor. Uma vez que, segundo ele, ocorre o movimento de supressão das diversidades, a negação das mais plurais vidas em todas as formas, e a negação das diversas existências e distintos hábitos. Esse afastamento fornece um leque com as mesmas opções, em que há um figurino geral, e se impõe na medida do possível uma única língua comum a todos.

As populações indígenas que sobreviveram ao processo de colonização, segundo Oliveira e Pinto (2011, p. 326-330), carregaram em seus corpos, culturas, práticas discursivas e sua própria existência, a resistência como elemento presente em suas epstemologias. A resistência à violência constante, os grupos indígenas implementam uma barreira frente a hegemonia epistêmica, posto a deterem práticas discursivas em que aspectos linguísticos agem dentro de um contexto, sem hierarquização.

A dita civilização denominou os povos que desconheciam como bárbaros e empreendeu uma guerra interminável contra eles, com o objetivo de modificá-los a sua imagem para que fossem civilizados, podendo assim integrar a humanidade (KRENAK, 2019). Aqueles que não se dobravam ou não eram conquistados, eram eliminados, pois a sua inexistência significaria que o centro do mundo continuaria privativo aos "povos civilizados". Assim, não haveria a necessidade de enxergar e reconhecer outros povos, não proporcionando a produção de uma ecologia de saberes. 


\subsection{O GENOCÍDIO INDÍGENA E SEU AGRAVAMENTO DURANTE A PANDEMIA DE} COVID-19.

Os povos indígenas americanos, conforme alude Santos (2007b, p. 40), em suas lutas e movimentos, não se afirmam no sentido de almejar emancipação social mas tratamento digno e respeito aos seus direitos e todos os elementos que os constituem. Proteção e promoção de direitos que deveriam ser empregados continuamente, porém que são ignorados propositalmente por aqueles que deveriam provê-los.

O Estado brasileiro constantemente pautou o tratamento usado com os povos indígenas, em uma franca tentativa de extermínio, como uma relação historicamente genocida, em que há a perspectiva de que os poucos sobreviventes restantes vivam em segregação, dentro de reservas que cada vez mais são engolidas pelo agronegócio, garimpo, exploração de recursos naturais, dentre outras ameaças, uma vez que são lugares que se opõe aos interesses da sociedade brasileira (MILANEZ ET AL, 2020, p. 2171)

As instituições governamentais permanecem inertes diante da destruição de povos indígenas, especialmente a esfera executiva, que na visão de Kopenawa e Albert (2015, p. 20), demonstra a muito tempo péssimos índices de desempenho quanto à preservação de direitos, de forma que os autores explicam resultar na nulidade de processos de demarcação de terras; programas de saúde ineficientes e omissos, que se mostram desastrosos; e principalmente a indiferença perante o genocídio que afeta constantemente os povos nativos, além do assassinato sistemático de lideranças indígenas.

Os indígenas tinham de ser extintos, uma vez que isso representa o avanço nacional, como afirma Milanez et al (2020, p. 2171), a parte indígena que sobreviveu as sucessivas matanças de sua população até hoje, se restringe a um contingente de milhares, evidenciando um escandaloso planejamento político do Estado brasileiro, que advém desde o período colonial até o republicano, que ambiciona extinguir esses povos.

A atribuição de características pejorativas às populações tradicionais, formavam o conjunto de justificativas de cunho ideológico para permitir a opressão europeia, de forma a transmutar sua imagem e perpetuas preconceitos até os dias de hoje, de modo a promover a inferiorização, exclusão e extinção das minorias étnicas, como podemos testemunhar na atualidade (MANDURUKU, 2012, p. 29-30).

Na pesquisa apresentada por Milanez et al (2020, p. 2172-2173) tem-se relatado acerca da cansativa tarefa de conviver com a necessid ade de prova da própria existência diariamente, mesmo que a morte já tenha sido decretada. Aqueles que estão em posições de poder determinaram a 
extinção dos povos indígenas. Não se trata de uma atuação apenas do governo, mas também de uma associação de instituições estatais que gradativamente vão negando a existência dessas pessoas, em que muitas comunidades indígenas não têm o reconhecimento pela FUNAI de maneira formal.

Mesmo que o Estado continue a negar a existência de povos indígenas, eles continuam existindo. A prova de vida não se limita aos órgãos governamentais, mas aos campos acadêmicos também. Diversas faces da violência se apresentam marcadamente no curso da história indígena, dentre elas a deslegitimação de suas origens e identidade, ação permanente na sociedade atual fomentada sobre o colonialismo (MILANEZ ET AL, 2020, p. 2173-2177).

Ao mesmo tempo que a humanid ade se distancia daquilo que seria o seu lugar, no cuidado da Terra, inúmeras empresas e indivíduos interessados tomam conta dos recursos naturais existentes. As pessoas vivem em ambientes artificialmente construído por aqueles que continuamente devastam florestas, rios, entre outros recursos (KRENAK, 2019). Demonstra-se a necessidade de aniquilar com grupos tradicionais e desocupar áreas para a exploração desmedida, objetivando tão somente o lucro.

Observa-se os perversos arranjos políticos que tem a finalidade de a exploração de áreas de preservação, territórios de comunidade quilombolas, reservas extrativistas e, especialmente, terras indígenas. Como meio para esse fim, promovem a retirada de proteções jurídicas a esses lugares em maior medida possível, assim como de locais onde se encontram populações que estão fora do ciclo iminente do mercado. Assim tendem a transformar essas terras em produtivas, na ótica capitalista, promovendo lucro aos interessados, como o agronegócio, a mineração e o setor agrário (KOPENAWA; ALBERT, 2015, p. 19).

A população originariamente brasileira sofreu com drásticas reduções advindas da mortandade por doenças, escravidão e guerra. A isto, veio em seguida o etnocídio com efeitos tão perversos quanto, que se deu por meio da desmoralização do comportamento e imposição da catequese; da apropriação de terras por indivíduos alheios, especialmente fazendeiros; e da fracassada tentativa de fixar-se em um lugar, com papel relevante, no mundo dominado por brancos. Assim, diante de poucas tribos que sobrevivem ilhadas frente a crescente população brasileira integrada a sociedade, sobra-se somente uma parcela dos povos indígenas originais (RIBEIRO, 2014).

O processo de modernização efetuou a dissipação dos sujeitos, que antes habitavam os campos e florestas, para sobreviverem limitados em favelas e outras áreas periféricas, de modo a serem a mão de obra barata em centros urbanos. Esses sujeitos foram retirados abruptamente dos coletivos os quais eram integrantes, expulsos de suas localidades originarias, e compelidos a 


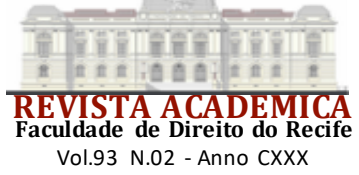

participar do moedor que chamam de humanidade. Sem uma forte ligação entre essas pessoas e suas raízes ancestrais, com aspectos que definem e fortalecem suas identidades, ela se perdem de si mesmas (KRENAK, 2019).

No advento da chegada dos colonizadores representou, de acordo com Ribeiro (2014), de início, a existência de dois lados opostos de uma implacável guerra biológica, uma vez que os brancos traziam consigo inúmeras novas doenças. Os europeus, sobreviventes pela resistência que desenvolveram as moléstias ao longo dos séculos, se punham de um lado. Do outro haviam os sujeitos indefesos, que nunca tiveram contato com nenhuma daquelas mazelas, e morriam desenfreadamente.

As ditas civilizações se impõe nesse modo, começando pelo alastramento de epidemias de doenças mortais, seguida pelo empreendimento de guerras exterminadoras e escravização. Contudo, não se trata do exaurimento dessa ação, sendo o princípio de um extermínio genocida e etnocida. Tendo em vista que o índio existente é uma pequena fração da tribo dizimada, em razão da morte de muitos na luta por liberdade e de maus-tratos, o aprisionamento que constituiu uma maneira de fazer os cativos, engendrou um genocídio de proporções imensas (RIBEIRO, 2014).

Ao longo dos séculos, epidemias de diversas doenças incidiram como trágicas reincidências sob os povos indígenas, no tocante a relação entre os colonizadores e essas populações, no território que hoje compõe o Estad o brasileiro. Apesar do lapso temporal aparentar ser distante, tais eventos ocorreram em um passado recente, de forma que persistem na lembrança coletiva de inúmeros povos (SANTOS; PONTES; COIMBRA JR, 2020, p. 01).

Dentro das delimitações da Amazônia Legal, no períod o que compreende a segunda metade do século XX, diversos povos que estavam totalmente ou parcialmente isolados, repentinamente e de forma violenta foram impactados por projetos assinalados como desenvolvimentistas. Posto terem seus territórios localizados em áreas nas quais passavam rodovias e que de modo célere estavam sendo ocupados por não indígenas. Como resultado essas populações foram devastadas pelo contágio de sarampo, tuberculose, influenza e malária (SANTOS; PONTES; COIMBRA JR, 2020, p. 01).

A pandemia chamou atenção para a dimensão das tragédias em curso, causando uma comoção de escala mundial. Apesar de se tratar de uma dramatização justificável, é perceptível a presença de sombras criadas em meio a visibilidade. Essas zonas que tornam acontecimentos e sujeitos invisíveis poderão se multiplicar em meio a um acontecimento como o alastramento do Covid-19, podendo ocorrer próximo a cada indivíduo (SANTOS, 2020).

Nesses tempos de dificuldades, em razão do crescimento vertiginoso da Covid-19, voltarse a atenção a vulnerabilidade dos grupos minoritários, muito embora os primeiros registros de 
casos se apresentaram entre as classes mais privilegiadas, estas que realizavam viagens internacionais, nas quais se infectavam e depois retornavam ao território brasileiro (ESTRELA ET AL, 2020, p. 3433).

Esses grupos detêm como ponto comum uma vulnerabilidade especial, agravada pela quarentena, e são, como denomina Santos (2020), componentes do Sul. Este Sul na concepção do autor não se trata de um espaço geográfico, mas sim o "espaço-social, político e cultural. É a metáfora do sofrimento humano injusto causado pela exploração capitalista, pela discriminação racial e pela discriminação sexual" (SANTOS, 2020).

No início do período pandêmico, e até os dias atuais, testemunhou-se inúmeras pessoas defenderem a manutenção de atividade econômica, um conformismo diante da mortandade, a afirmação de que é inevitável a morte. Essas falas influem em núcleos familiares inteiros, uma vez que todos são suscetíveis. Se percebe a banalização do poder da palavra e da vida (KRENAK, 2020). E essa ação afeta profundamente grupos tradicionais que contam com menor proteção, passando de uma banalização de palavras ditas a um verdadeiro desprezo à essas vidas e um projeto de extermínio.

Para Krenak (2019), não há de se retirar a responsabilidade e o grau de agravamento da estrutura que possibilitou o avanço colonialista, contudo, há de se reconhecer que a sucessão de eventos ocorridos se trata de um desastroso reflexo daquela época. Da mesma forma, atualmente vivemos em um desastroso conjunto, que alguns nomeiam como "caos social, desgoverno geral, perda de qualidade no cotidiano, nas relações, e estamos jogados no abismo" (KRENAK, 2019).

Como afirma Santos (2020), a crise permanente que se configura, não detém como objetivo a sua resolução, uma vez que a sua manutenção legitima a concentração de riquezas e sabota possíveis medidas capazes de impedir a catástrofe ecológica. A pandemia se tornou um mecanismo de agravo em toda a situação caótica que a população mundial já se encontra, estando aí sua periculosidade específica. Pode-se perceber, que em alguns países, os sistemas de saúde se encontravam melhor preparados para atender suas populações há anos atrás, e não nos dias atuais.

A afirmação de que economia não pode parar é sempre disparada por governos e seus chefes tolos, uma vez que a atividade econômica é uma atividade essencialmente dependente da ação humana, se há um perigo para as pessoas, quaisquer atividades que delas dependam, estarão em perigo (KRENAK, 2020). Quem não está presente nesse círculo de produção econômica, é totalmente descartável, sendo alvo do extermínio.

O autor Ailton Krenak, na obra "A vida não é útil” (2020), destacou que o presidente da República havia dito que os brasileiros tiveram contato com esgoto e não tinha consequências à

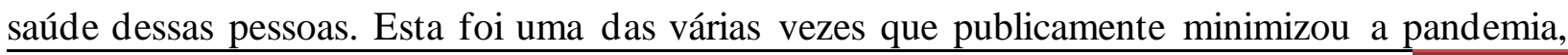


utilizando-se de argumentos pífios, versando um exercício que Krenak (2020) afirma se tratar de necropolítica, de uma ação com a finalidade promover a morte, por meio de uma mentalidade que alcançou escalas mundiais.

O projeto de extinção de populações nativas inteiras, discorre de um terror presente no exercício da dominação, sob o pretexto de melhoria e avanço da sociedade. $\mathrm{O}$ terror, nas palavras de Mbembe (2016, p. 130), não tem somente um elo à convicção utópica no poder ilimitado do raciocínio humano, mas está ligado às várias modalidades de domínio e emancipação, apoiadas principalmente em noções iluministas acerca do que seria a verdade e o erro, a realidade e o simbolismo.

O contágio por Covid-19, evidenciou a tensão existente e as diversas dimensões acerca da atuação do Estado na implementação de políticas públicas direcionadas a minorias étnico-raciais no cenário brasileiro. Restam claros, além dos impactos, as singularidades da persistência e contraposição do movimento indígena, em sua esfera etnopolítica. As questões indígenas, diante da situação pandêmica, detêm implicações que se estendem desde a inseguridade alimentar, perpassam pelo temor de se externarem aos domínios das aldeias, até a violência de caráter simbólico quanto a impossibilidade de celebrar os ritos funerários tradicionais, no caso de pessoas falecidas que forma acometidas pela doença (SANTOS; PONTES; COIMBRA JR, p. 01, 2020).

A vulnerabilidade socioambiental e política das populações indígenas se destacou e ampliou com a crise sanitária ocasionada pelo coronavírus. No conjunto situacional da violação de direitos, dentro da dita normalidade, pertencer a minoria indígena brasileira significa sobreviver diante das precariedade de saneamento e deficiência habitacional, lutar contra a invasão de territórios e suas destruições; conviver com a crescente escassez de alimento e ausência de agua potável acessível diariamente; lidar com taxas elevadas da mortalidade infantil, bem como a desnutrição que atinge uma parcela considerável de crianças que estão abaixo do cinco anos de idade, o acometimento de doenças infecciosas e parasitarias que ocasionam esse adoecimento e morte; e, dentro do contexto urbano, ser invisibilizado e desvalorizado como ser humano (SANTOS; PONTES; COIMBRA JR, 2020, p. 02).

A atuação estatal contribui em muito para o mecanismo de enfraquecimento e potencial extinção de grupos indígenas. O último homem da etnia Juma, faleceu em decorrência das complicações da infecção de Covid-19, e este se mostra como um claro exemplo de como a ausência de medidas sanitárias no combate da pandemia pode ser utilizada como uma ferramenta de genocídio. O mesmo individuo é ainda exemplo de ineficiência de preservação dos direitos indígenas e da ação comissiva no sentido de promover a mortandade desse povo, uma vez que era sobrevivente de um massacre que dizimou sessenta pessoas dessa etnia (GORTÁZAR, 2021). 


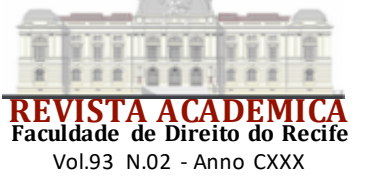

Estas situações direcionam para perversidade quanto a saúde, no tocante ao contexto étnico-racial, dominante no país, fomentando circunstâncias propicias para epidemia, como meio para que siga sua finalidade exterminad ora, como ocorre com a pandemia de Covid -19 atualmente. Muito embora, o sistema público de saúde, detenha um nicho voltado para atenção primaria à saúde da população indígena, a vagarosidade na resposta a doença, articulada com decisões questionáveis de controle de contágio e tratamento, levaram a uma catástrofe (SANTOS; PONTES; COIMBRA JR, 2020, p. 02).

As modalidades modernas de formas de eliminar a vida, lhe subordinando ao poder de morte, da necropolítica, promoveram novas configurações nas relações de resistência, sacrifício e horror. No mundo contemporâneo, o necropoder, que promove a destruição e se pauta na constância da morte como ferramenta de poder, permitiu uma existência social única, que submete populações a cond ições de vida que os assinalam como "mortos-vivos" (MBEMBE, 2016, p. 146).

Diante da atuação doEstado, que primeiro inviabiliza, segrega e retira direitos, em seguida, retira a vida das populações indígenas, estes enfrentam desafios de resistência para manter seu conjunto étnico-cultural vivo, além de seus corpos. São os mortos-vivos presentes na atualidade e que ao mesmo tempo estão ausentes, diante da posição inferior e invisibilizada que estão colocados.

\section{CONCLUSÃO}

A existência de uma divisão social não deve necessariamente significar a supressão do outro lado, a desconsideração da existência de sujeitos, lugares e saberes que sem encontram do outro lado da linha, devendo-se haver a coexistência dos atores de ambos os lados. Contudo, não é esta a ação recorrente quanto as populações indígenas, que são marginalizadas e sistematicamente eliminados, de todas as formas possíveis.

A ameaça a existência dos povos tradicionais e de sua cultura sempre foi latente, como se observa pela redução populacional e da influência cultural após o início do colonialismo. Desta forma se tornou uma política estatal, a fim de atender interesses diversos e alheios a realidade indígena, o desrespeito aos direitos dessas populações, seja a suas terras, ao exercício de seus costumes, ou suas vidas.

Os efeitos do Covid-19 se mostraram implacáveis quanto a afetação da saúde de boa parte da população brasileira, mas tem especial crueldade quando incidem sobre povos tradicionais. Em todos os ciclos sociais é possível ver os efeitos que a doença proporcionou a população e as políticas de desenvolvimento do Estado. Inúmeras pessoas foram acometidas pela doença, 


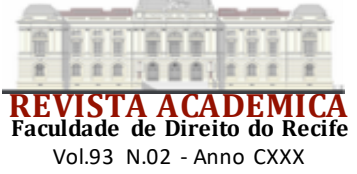

inclusive perdendo suas vidas, havendo um impacto consideravelmente mais a depender em que se colocação estavam no lado de cá ou de lá da linha abissal.

A ocorrência da pandemia se mostrou uma oportunidade reforçar a política de morte implementada pelo Estado para com os indígenas, por meio de ações e omissões, alargando ainda mais as dificuldades enfrentadas por essas pessoas, chegando até a ao extermínio completo de etnias, se tratando de um genocídio.

No panorama que se agravou de maneira crescente, não havendo esperança de significativa melhora quanto ao tratamento a ser empregado com as populações indígenas. Registra-se que há uma nova redução populacional, que foi gerada pela ação estatal comissiva elevando a um novo patamar de extinção.

O uso de armas biológicas como meio de domínio ou destruição não se trata de uma modalidade nova, assim como a frequente demarcação dos sujeitos como invisíveis a fim de suplantar suas influências na sociedade. Desse modo, novamente utiliza-se de uma arma, que se alastrou inicialmente de maneira não intencional, mas que foi usada pela ação estatal como meio de potencializar o genocídio corrente e acelerar o apagamento dos povos indígenas.

\section{REFERÊNCIAS}

CAMPOS, Ricardo Ribeiro. O genocídio e a sua punição pelos tribunais internacionais. Revista de Informação Legislativa, Brasília, v. 45, n. 178, p. 91-103, abr./jun. 2008. Disponível em: http://www2.senado.leg.br/bdsf/handle/id/176525. Acesso em: 24/07/2021.

CUNHA, Manuela Carneiro de. Cultura com aspas e outros ensaios. 1. ed. São Paulo: Cosac \& Naify, 2009.

ESTRELA, Fernanda Matheus et al. Pandemia da Covid-19: refletindo as vulnerabilidades a luz do gênero, raça e classe. Ciências \& Saúde Coletiva, Rio de Janeiro, v. 25, n. 9, p. 3431-3436, set. 2020. Disponível em: http://www.scielo.br/scielo.php?script=sci_arttext\&pid=S1413$81232020000903431 \& \operatorname{lng}=$ en\&nrm=iso. Acesso em: 18 out. 2020.

GORTÁZAR, Naiara Galarraga. O último ancião Juma morre de covid-19 e leva para o túmulo a memória de um povo aniquilado no Brasil. El País, 2021. Disponível em: https://brasil.elpais.com/brasil/2021-02-19/o-ultimo-anciao-juma-morre-de-covid-19-e-levapara-o-tumulo-a-memoria-de-um-povo-aniquilado-nobrasil.html\#: :text=Aruk\%C3\%A1\%20Juma\%2C\%20sobrevivente\%20de\%20um,entre\%2012.0 00\%20e\%2015.000\%20membros. Acesso em: 25 jul. 2021.

KOPENAWA, Davi; ALBERT, Bruce. A queda do céu: Palavras de um xamã yanomami. Tradução Beatriz Perrone-Moisés; prefácio de Eduardo Viveiros de Castro. 1.ed. São Paulo: Companhia das Letras, 2015.

KRENAK, Ailton. A vida não é útil. 1. ed. Companhia das Letras: São Paulo, 2020. 


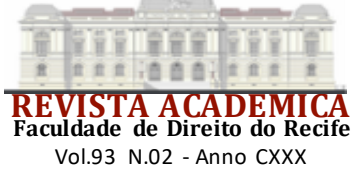

KRENAK, Ailton. Ideias para adiar o fim do mundo. 1. ed. Companhia das Letras: São Paulo, 2019.

MANDURUKU, Daniel. O caráter educativo do movimento indígena brasileiro (1970-1990). São Paulo: Paulinas, 2012. Coleção educação em foco: Série educação, história e cultura.

MARCONI, Marina de Andrade; LAKATOS, Eva Maria. Metodologia do trabalho científico: procedimentos básicos, pesquisa bibliográfica, projeto e relatório, publicações e trabalhos científicos. 7. ed. São Paulo: Atlas: 2011.

MILANEZ, Felipe et al. Existência e diferença: O racismo contra os povos indígenas. Revista Direito e Práxis, Rio de Janeiro, v. 10, n. 3, p. 2161-2181, 2019. DOI: https://doi.org/10.1590/2179-8966/2019/43886. Disponível em: http://scielo.br/scielo.php?script=sci_arttext\&pid=S2179-8966201900030216. Acesso em: 25 jul. 2021.

MBEMBE, Achille. Necropolítica: biopoder, soberania, estado de exceção, política da morte. Tradução de Renata Santini. Arte \& Ensaios. Revista do ppgav/eba/ufrj, Rio de Janeiro, n. 32, p. 123-151, dez. 2016. Disponível em: https://revistas.ufrj.br/index.php/ae/article/view/8993. Acesso em: 24 jul. 2021.

OLIVEIRA, Elismênnia Aparecida; PINTO, Joana Plaza. Linguajamentos e contra-hegemonias epistêmicas sobre linguagem em produções escritas indígenas. Linguagem em (Dis)curso, v. 11, n. 2, p. p. 311-335, out. 2011. ISSN 1982-4017. Disponível em: http://www.portaldeperiodicos.unisul.br/index.php/Linguagem_Discurso/article/view/688. Acesso em: 24 jul. 2021.

\section{ORGANIZAÇÃODAS NAÇÕES UNIDAS (ONU). Convenção para a prevenção e a} repressão do crime de Genocídio. Paris, 11 dez.1948.

PINHEIRO, Priscila Tinelli; BUSSINGUER, Elda Coelho de Azevedo. Boaventura de Sousa Santos e a lógica do pensamento abissal: uma análise a partir do método dialético. Revista de Sociologia, Antropologia e Cultura Jurídica, Curitiba, v. 2, n. 2, p. 890- 908, jul./dez. 2016. Disponível em: https://www.indexlaw.org/index.php/culturajuridica/article/view/1501. Acesso em: 18 out. 2020.

RIBEIRO, Darcy. O povo brasileiro: a formação e o sentido do Brasil [recurso eletrônico] - 1 . ed. São Paulo: Global, 2014.

SANTOS, Boaventura de Sousa. A Cruel Pedagogia do Vírus. 1. ed. São Paulo: Boitempo, 2020. Coleção Pandemia Capital.

SANTOS, Boaventura de Sousa. O fim do império cognitivo: a afirmação das epstemologias do sul. 1. ed. Belo Horizonte: Autêntica Editora, 2019.

SANTOS, Boaventura de Sousa. Para descolonizar Occidente: más alla del pensamiento abismal. 1. ed. Buenos Aires: Consejo Latinoamericano de Ciencias Sociales - CLACSO; Prometeo Libros, 2010. 


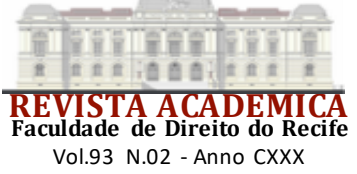

SANTOS, Boaventura de Sousa. Para além do pensamento abissal: das linhas globais a uma ecologia de saberes. Novos Estudos - CEBRAP, São Paulo, n. 79, 2007a, p. 71-94. Disponível em: http://www.scielo.br/scielo.php?script=sci_arttext\&pid=S0101 $33002007000300004 \& \operatorname{lng}=$ en\&nrm=iso. Acesso em: 18 out. 2020.

SANTOS, Boaventura de Sousa. Renovar a teoria crítica e reinventar a participação social. São Paulo: Boitempo, 2007b.

SANTOS, Ricardo Ventura; PONTES, Ana Lucia; COIMBRA JR, Carlos E. A. Um "fato social total": COVID-19 e povos indígenas no Brasil. Cadernos de Saúde Pública, Rio de Janeiro, v. 36, n. 10, Set. 2020. Disponível em: http://cadernos.ensp.fiocruz.br/csp/artigo/1194/um-fatosocial-total-covid-19-e-povos-indigenas-no-brasil. Acesso em: 24 jul. 2021.

SILVA, Maria do Socorro Borges da. Entre as linhas abissais do pensamento e da formação, pensando práticas de educar em direitos humanos que atravesse o muro das violências e das exclusões. Revista do Programa de Pós- Graduação em Educação da UFPI. Linguagens, Educação e Sociedade, Teresina, ano 22, n. 36, jan./jul. 2017. Disponível em: https://revistas.ufpi.br/index.php/lingedusoc/article/view/7532. Acesso em: 18 out. 2020.

VERGNE, Celso de Moraes; VILHENA, Junia de;ZAMORA, Maria Helena; ROSA, Carlos Mendes. A palavra é... genocídio: a continuidade de práticas racistas no Brasil. Psicologia \& Sociedade [online]. Recife, v. 27, n. 03, p. 516-528, 2015. Disponível em: https://doi.org/10.1590/1807-03102015v27n3p516. Acesso em: 25 jul. 2021. 